\title{
THE DIFFERENT INTRACELLULAR ACTION POTENTIALS OF FAST AND SLOW MUSCLE FIBRES $^{1}$
}

\author{
WILLEMIEN WALLINGA-DE JONGE, FRANS L.H. GIELEN, PETER WIRTZ *, PAUL DE JONG and JAN BROENINK
}

Bio-Information Group, Department of Electrical Engineering, Twente University of Technology, P.O. Box 217, 7500 AE Enschede and

* Department of Cytology and Histology, University of Nijmegen, $6500 \mathrm{HB}$ Nijmegen (The Netherlands)

(Accepted for publication: December 19, 1984)

The shape of motor unit action potentials (MUAPs) is determined by a lot of factors. In modelling the MUAP 3 groups of parameters can be distinguished (Griep et al. 1982). First, the geometrical parameters of the motor unit fibres in the muscle. Second, the action potential data at fibre level. Thirdly, the conduction properties of the tissue between the active fibres and the recording electrode.

Aspects of the geometry of the muscle fibres have been described in some detail in our MUAP model (Griep et al. 1982). Next, the conductivity properties of the muscle tissue (the parameters of the third group) have been studied in the relevant EMG frequency range (Gielen et al. 1984). The anisotropy of the tissue appears to depend on the scale of registration. In both qualitative and quantitative EMG modelling this aspect has to be taken into account. The data in this paper concern the action potential linked parameters, especially the intracellular action potential (IAP). By the use of motor unit stimulation an IAP can be linked to the type of the fibre. We show that the shape of the action potentials measured inside fast fatiguable (EDL) fibres differs from that inside slow (soleus) fibres of the rat.

Some of the differences have already been indicated for rat muscle by Yonemura (1967), Albuquerque and Thesleff (1968), Fedorov (1969), Hanson (1974) and McArdle et al. (1980). In their experiments, however, a mixture of different fibre

\footnotetext{
1 The work was supported in part by a grant from the Netherlands Organisation for the Advancement of Pure Research (ZWO).
}

types (e.g., Zuurveld, thesis University of Nijmegen 1984, for rat muscles) may have hidden the real differences between the fibre types.

Theoretically the extracellular single fibre action potential (SFAP) can be considered as the second derivative of the intracellular signal (Rosenfalck 1969). So the shape of the IAP is reflected in the SFAP; important aspects are the slope of the de- and re-polarization phases. The variation in the values of the slopes reported in the literature is large (Luff and Atwood 1972; Ludin 1977) even when the experimental conditions are rather comparable. Our results show remarkable differences in slope between IAPs of fast and slow fibres. The mean values and the standard deviations of 8 parameters derived from IAPs are presented for populations of fast fatiguable and slow fibres.

\section{Methods and Materials}

\section{(1) Animal and muscle preparation}

The measurements were carried out in vivo, on the right $\mathrm{m}$. extensor digitorum longus (EDL) and right $\mathrm{m}$. soleus in the hind limb of the rat. The rats (Wistar, male, 3-4 months old, $0.30-0.35 \mathrm{~kg}$ ) were anaesthetized intraperitoneally with pentobarbital sodium. The initial dose was $70 \mathrm{mg} / \mathrm{kg}$. On an average $15 \mathrm{mg} / \mathrm{kg}$ was given in addition every half hour. EDL and soleus muscles were used in separate experiments in different rats. The muscle was in vivo as described before (Wallinga-De Jonge et al. 1980). Single motor units were stimulated with the epimuscular stimulation method of Griep et al. (1980). The body temperature of the rat and of the 
muscle were controlled and regularly checked. The muscle temperature was $35 \pm 1^{\circ} \mathrm{C}$. All experiments were performed at optimum twitch length of the whole muscle. The optimum twitch lengths of motor units were about equal to the optimum twitch length of the whole muscle (unpublished data).

Force patterns of the muscles and the motor units were measured via an isometric force transducer (Harvard Apparatus Inc., model 383, range $0-1 \mathrm{~N}$ ). The stiffness of the transducer was $2 \times 10^{4} \mathrm{Nm}^{-1}$ and the sensitivity $2 \mathrm{VN}^{-1}$. The insertion tendons were tied with stiff thread to the transducer.

\section{(2) Electrodes and recording systems}

Three types of electrode were used (see Fig. 1). Electrodes for single motor unit stimulation. These consisted of two PtIr (10\% Ir) wires coated with teflon. At the tip only the cross-section of the wires (PtIr $25 \mu \mathrm{m}$ diameter) was bare. The electrodes were connected to a floating current source. The current was adjustable $(0-60 \mu \mathrm{A})$; the pulse width used was $50 \mu \mathrm{sec}$.

EMG electrodes to record motor unit action potentials (MUAPs). Continuous monitoring of the MUAP during the experiment was important in order to check that the same motor unit was stimulated throughout the experiment. MUAP and single fibre EMG data in relation with fibre type will be published separately. The EMG electrodes were trimell-coated karma wires of $25 \mu \mathrm{m}$ or 50 $\mu \mathrm{m}$ diameter. The tip was bevelled at an angle of about $45^{\circ}$ for easy penetration into the muscle. The electrodes were connected to EMG preamplifiers (input impedance $10^{12} \Omega / / 3 \mathrm{pF}$ ), which were situated at a distance of about $5 \mathrm{~cm}$ of the muscle. The bandwidth of the EMG recording system was $0.1 \mathrm{~Hz}-30 \mathrm{kHz}(-3 \mathrm{~dB})$.

Glass micropipettes to record intracellular action potentials (IAPs). The overall muscle length was fixed, but a single motor unit contraction caused internal movements. The flexibility of the pipette prevented movement artefacts in the majority of the IAPs. The taper of the glass micropipettes was chosen in such a way that the impedance of the pipette was maintained below $55 \mathrm{M} \Omega$ ( $3 \mathrm{M} \mathrm{KCl}$ solution in the pipette). The tip diameter was about $0.2 \mu \mathrm{m}$.
The pipette was connected to a recording system (model M707 microprobe system of W.P. Instruments Inc.) by means of an $\mathrm{Ag} / \mathrm{AgCl}$ electrode. With the capacity compensation facility of the microprobe system the frequency bandwidth was optimized. However, the capacitances distributed near the very tip could not be compensated. The bandwidth of the micropipette recording system was checked in each penetrated fibre by passing a sinusoidal current with an amplitude of $1 \mathrm{nA}$ through the micropipette. The resulting potential across the pipette tip was measured at $100 \mathrm{~Hz}$ with the WPI. Then the frequency of the current was increased until a $3 \mathrm{~dB}$ decrease of the measured potential was observed. The frequency bandwidth was $0 \mathrm{~Hz}$ to more than $5 \mathrm{kHz}(-3 \mathrm{~dB})$. The high frequency limit varied between 5 and $15 \mathrm{kHz}$ depending on the actual tip impedance of the pipette. The tip potential of the electrodes was less than $5 \mathrm{mV}$.

\section{(3) Signal processing}

The twitch of the motor unit, the motor unit action potentials recorded with 3 electrodes (MUAPs) and the intracellular potential were displayed on storage scopes (HP 1201 A) for visual control. Amplification of all signals (pre-sampling amplifiers, Neff model 128 DC amplifier) was used for maximum resolution in the subsequent analog-digital conversion. All recorded signals were started 0.5 msec before stimulation of the motor unit. The use of a transient recorder with an A-D converter for each separate signal enabled parallel A-D conversion and storage of the digital values (10-bit $2 \mathrm{k}$ ). Only two different parallel sample frequencies could be effective in the transient recorder. The sample frequencies chosen were 10 $\mathrm{kHz}$ for the twitch and $100 \mathrm{kHz}$ for all other signals. After registration the signals were transmitted to a PDP 11/40 computer and stored on disc.

\section{(4) Experimental procedures}

The EMG recording electrodes were inserted in the muscle about half way between the tendon and the end-plate region. Subsequently the stimulation of a single motor unit was induced with the epimuscular stimulation method: with a PtIr wire 


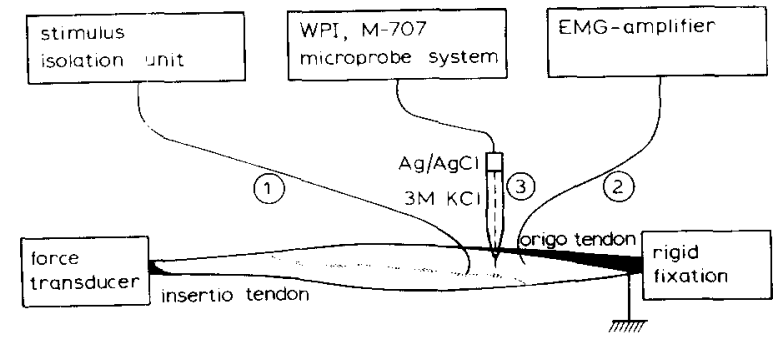

Fig. 1. Scheme of the experiments. 1: motor unit stimulation; current amplitude 5-60 $\mu \mathrm{A}$, pulse width $50 \mu \mathrm{sec}$. 2: an example of an EMG electrode, recording with respect to earth. 3: the WPI system, including capacity compensation and bandwidth control.

electrode positioned on the surface of the muscle a single motor unit was triggered via excitation of an axon terminal (Griep et al. 1980). The territory of the motor unit was scanned using an EMG electrode with a diameter of $50 \mu \mathrm{m}$ on the surface of the muscle. This electrode was moved stepwise in a direction transverse to the muscle fibres. At each position the amplitude of the MUAP was measured. In the area with large amplitudes the micropipette penetrations were executed. The offset potential of the pipette was compensated when the tip rested on the surface of the muscle. The micropipette was 'tapped' with steps of $5 \mu \mathrm{m}$ into the muscle until a fibre was penetrated. One additional step was made, then the pipette capacity was compensated and the bandwidth was determined. The subsequent stimulation of the motor unit revealed whether the pipette was in a fibre of the motor unit or not. If so, the motor unit force, the 3 MUAPs and the IAP were stored on disc. The pipette was moved stepwise downwards until if left the fibre. The pipette was not moved more than $1.5 \mathrm{~mm}$ below the muscle surface. After retraction of the pipette the whole procedure was repeated at a position $100 \mu \mathrm{m}$ away from the former insertion point (in a direction transverse to the muscle fibres). The experimental arrangement is shown schematically in Fig. 1.

\section{(5) Determination of motor unit type}

The EDL and soleus muscles of the rat contain different fibre types. In the EDL the majority of the fibres are fast contracting, but in those fast fibres the glycolytic oxidative character varies sub- stantially. To establish the type of the EDL motor units we proceeded as follows. At the end of the experiments (after up to 14 successful fibre penetrations or earlier in a deteriorating animal) the motor unit glycogen was depleted by continuous stimulation. Two intervals were used ( 25 and $100 \mathrm{msec}$ ), both equally effective for glycogen depletion. The stimulation was continued until the force was diminished to less than $20 \%$ of the original level. Next, the muscle was rapidly fixed in a small clamp at the optimum twitch length, immersed in white of egg (Rahman and Luttrell 1962), and frozen in isopentane at about $-150^{\circ} \mathrm{C}$ within 2 min after the stimulation stopped. After 2 min in isopentane the muscle was transferred to liquid nitrogen. The muscle was removed from the clamp and stored at $-180^{\circ} \mathrm{C}$ or $-90^{\circ} \mathrm{C}$ until sectioning in a cryostat. To detect the glycogendepleted fibres the sections were reacted for tissue glycogen (periodic acid Schiff, PAS) and for phosphorylase (EC 2.4.1.1). Especially the phosphorylase staining proved to be a valuable tool to detect the stimulated fibres (Wirtz et al. 1983a). To describe the histochemical type myofibrillar ATPase (preincubation $\mathrm{pH}$ 4.35, ATPase, EC 3.6.1.3), succinic dehydrogenase (SDH, EC 1.3.99.1) and glycerolphosphatedehydrogenase (GPOX, EC 1.1.99.5) were used (Wirtz et al. 1983b). All EDL motor units studied proved to be of the fast twitch glycolytic (FTG) type. These motor units had contraction times of 9-12 msec at optimum twitch length of the muscle. The stimulation period necessary to reduce the twitch force to less than $20 \%$ of the starting twitch value was 1-5 min.

Until now we have not been successful in the glycogen depletion of soleus motor units. In our experiments with motor unit stimulation at the muscle surface it is not possible to close and reopen in turn the blood flow to the muscle. In this way Kugelberg and Thornell (1983) depleted slow motor units of the soleus of Sprague-Dawley rats. The physiological motor unit types in the (Wistar) rat soleus are slow and intermediate (Close 1967). The contraction times of the slow and the intermediate motor units are quite different, $>35$ and $<25 \mathrm{msec}$ respectively at $35^{\circ} \mathrm{C}$ (Close 1967). All soleus motor units used in our study had contraction times $>29 \mathrm{msec}$ at optimum twitch 
length and were considered to belong to the slow type (for intermediate motor units we found contraction times $<20 \mathrm{msec}$ ).

With the approach described we selected muscle fibres belonging to 2 extreme categories so that the differences would be as clear as possible.

\section{Results}

\section{(1) Characteristics of intracellular action potential}

An example of an IAP is shown in Fig. 2. The characteristics studied are indicated in that figure. It was necessary to define them to enable comparison of the IAPs of 2 fibre types. Some of the characteristics (the resting membrane potential, the amplitude of the IAP and the maximum rates of depolarization and repolarization) could be compared with the literature data (see Results, section 4). The other characteristics were chosen in order to get additive information about the time course of the IAP. The characteristics were calculated by a computer. The peak-peak noise level was about $1 \mathrm{mV}$; the data concerning potentials are given in $\mathrm{mV}$. The rates were determined by linear regression over 5 samples; the value was attributed to the centre sample (sample time $10 \mathrm{nsec}$ ). The rates are given in terms of $\mathrm{V} / \mathrm{sec}$ due

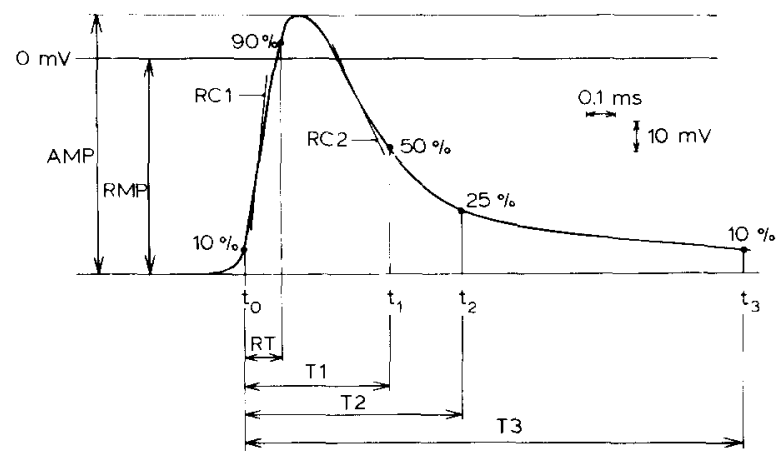

Fig. 2. An intracellular action potential of an FTG EDL fibre, displayed schematically to indicate the characteristics used. AMP, amplitude ( $\mathrm{mV})$; RMP, resting membrane potential $(\mathrm{mV})$; $\mathrm{RC} 1$, max. rate of depolarization $(\mathrm{V} / \mathrm{sec})$; $\mathrm{RC} 2$, $\max$. rate of repolarization $(\mathrm{V} / \mathrm{sec}) ; \mathrm{RT}$, rise time (time between 10 and $90 \%$ in dep. phase) (msec); $\mathrm{T}_{1}$, time between $10 \%$ in dep. and $50 \%$ in rep. phases (msec); $\mathrm{T}_{2}$, time between $10 \%$ in dep. and $25 \%$ in rep. phases (msec); $\mathrm{T}_{3}$, time between $10 \%$ in dep. and $10 \%$ in rep. phases (msec). to the standard deviation values. Times are given in $0.01 \mathrm{msec}$.

Beforehand it was not clear which variation in shape could be expected for the IAPs. After the experiments described in this paper we formulated criteria for selection of IAPs used in the procedure to state the characteristic shapes of IAPs of fast and slow fibres. The selection criteria were the following five:

- clear evidence for the motor unit type: either histological for an FTG unit in the EDL or physiological for a slow unit in the soleus;

- only the first IAP records after impalement of the fibre in order to avoid possible different shapes due to membrane damage caused by contraction movement;

- stable resting membrane potential of the fibres after impalement preceding the action potential;

- resting membrane potential $<-40 \mathrm{mV}$;

- action potential amplitude $>60 \mathrm{mV}$.

Sometimes it was possible to record 30 action potentials in the same fibre without any change in the resting membrane potential and the shape of

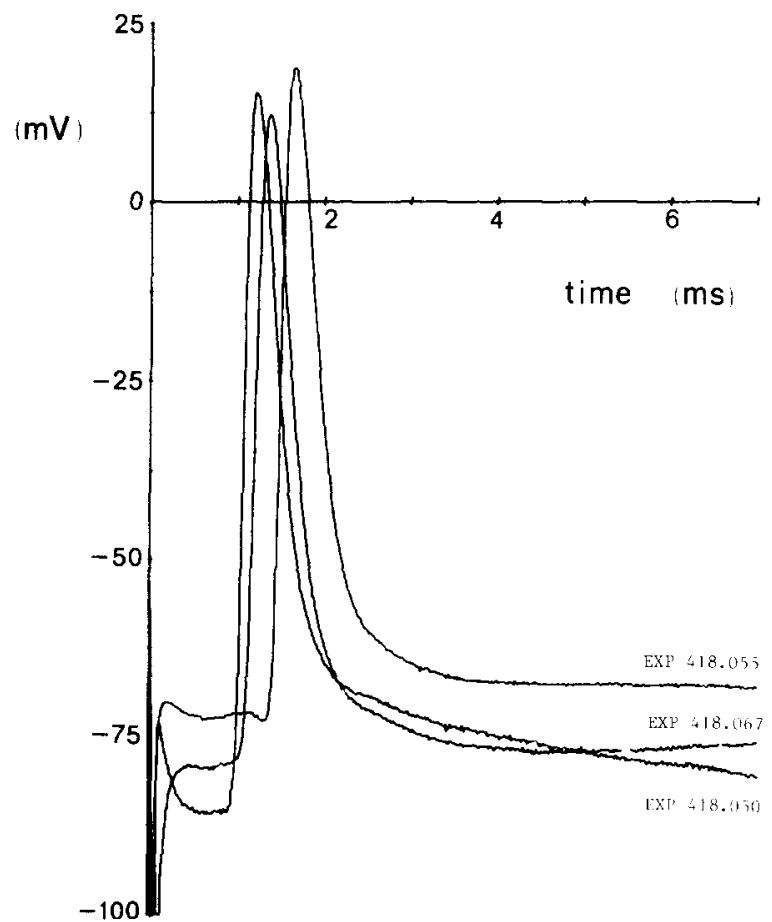

Fig. 3. Three intracellular action potentials of fibres of one FTG EDL motor unit. 
the IAP. More frequently changes did occur during prolonged stimulation. Simultaneous changes often observed were: a shift of the resting membrane potential to less negative values; a decrease in the amplitude; and a decrease in the maximum rates of the rising and declining phases of the IAP.

\section{(2) The IAPs of FTG EDL fibres}

Fig. 3 shows IAPs of 3 fibres belonging to the same motor unit. Note the variation in the resting membrane potential, in the amplitude and in the repolarization phase, especially in the last part of it. In EDL fibres a slow repolarization towards the resting membrane potential was often observed.

The shift along the time axis between the IAPs arose from the total dispersion in the propagation time along the nerve twigs, in the delay time in the end-plates and in the propagation time along the muscle fibres. The time dispersion reached values up to $2 \mathrm{msec}$ (in soleus motor units also).

For 3 FTG EDL units 10 IAPs or more were recorded. A comparison of the mean values of IAP characteristics of these 3 motor units showed no significant difference between the units (Table I

\section{TABLE I}

Data of intracellular action potentials of FTG EDL and slow soleus fibres. In the upper part the mean and the standard deviation (measure of dispersion around the mean) of the characteristics introduced in Fig. 2 are indicated per motor unit (motor unit code); $n$ represents the number of action potentials recorded per motor unit. In the lower part mean and standard deviation of the two fibre populations are given. The Student $t$ test was used to evaluate the statistical differences in the means of the FTG EDL and the slow soleus fibres. $O=$ not significant $(\alpha=1.0 \%) ; *=$ significant difference $(\alpha=0.5 \%)$ and $* *=$ significant difference $(\alpha=0.1 \%)$.

\begin{tabular}{|c|c|c|c|c|c|c|c|c|c|}
\hline $\begin{array}{l}\text { MU } \\
\text { code }\end{array}$ & & $\begin{array}{l}\text { RMP } \\
(\mathrm{mV})\end{array}$ & $\begin{array}{l}\text { AMP } \\
(\mathrm{mV})\end{array}$ & $\begin{array}{l}\mathrm{RCl} \\
(\mathrm{V} / \mathrm{sec})\end{array}$ & $\begin{array}{l}\mathrm{RC} 2 \\
(\mathrm{~V} / \mathrm{sec})\end{array}$ & $\begin{array}{l}\mathrm{RT} \\
\text { (msec) }\end{array}$ & $\begin{array}{l}\mathrm{T}_{1} \\
\text { (msec) }\end{array}$ & $\begin{array}{l}\mathrm{T}_{2} \\
\text { (msec) }\end{array}$ & $\begin{array}{l}\mathrm{T}_{3} \\
\text { (msec) }\end{array}$ \\
\hline \multicolumn{10}{|l|}{$E D L$} \\
\hline 004 & M & -77 & 91 & 690 & -195 & 0.14 & 0.50 & 0.74 & 1.55 \\
\hline$(n=10)$ & S.D. & 7 & 8 & 80 & 15 & 0.01 & 0.02 & 0.04 & 0.45 \\
\hline 107 & M & -80 & 94 & 680 & -190 & 0.15 & 0.53 & 0.79 & 1.90 \\
\hline$(n=10)$ & S.D. & 8 & 8 & 110 & 25 & 0.02 & 0.04 & 0.16 & 0.70 \\
\hline 110 & M & -82 & 95 & 690 & -180 & 0.15 & 0.57 & 0.80 & 1.30 \\
\hline$(\mathrm{n}=2)$ & S.D. & 8 & 10 & 70 & 15 & 0.01 & 0.03 & 0.06 & 0.20 \\
\hline 111 & $\mathrm{M}$ & -77 & 102 & 700 & -210 & 0.16 & 0.55 & 0.78 & 1.50 \\
\hline$(n=4)$ & S.D. & 3 & 5 & 80 & 25 & 0.01 & 0.04 & 0.05 & 0.10 \\
\hline 418 & M & -79 & 92 & 610 & -180 & 0.16 & 0.56 & 0.79 & 1.55 \\
\hline$(n=14)$ & S.D. & 5 & 6 & 90 & 20 & 0.02 & 0.04 & 0.05 & 0.60 \\
\hline 421 & $\mathbf{M}$ & -78 & 95 & 660 & -190 & 0.15 & 0.54 & 0.75 & 1.65 \\
\hline$(n=5)$ & S.D. & 5 & 8 & 80 & 20 & 0.01 & 0.03 & 0.05 & 0.60 \\
\hline \multicolumn{10}{|l|}{ Soleus } \\
\hline 412 & $\mathbf{M}$ & -79 & 92 & 450 & -135 & 0.22 & 0.77 & 1.03 & 1.45 \\
\hline$(n=5)$ & S.D. & 9 & 9 & 100 & 15 & 0.02 & 0.03 & 0.03 & 0.15 \\
\hline 414 & M & -66 & 76 & 290 & -110 & 0.28 & 0.87 & 1.11 & 1.40 \\
\hline$(n=4)$ & S.D. & 6 & 5 & 50 & 15 & 0.03 & 0.10 & 0.12 & 0.15 \\
\hline 415 & $\mathrm{M}$ & -74 & 85 & 410 & -130 & 0.23 & 0.78 & 1.05 & 1.50 \\
\hline$(n=4)$ & S.D. & 1 & 2 & 30 & 5 & 0.01 & 0.01 & 0.02 & 0.05 \\
\hline \multicolumn{10}{|l|}{$E D L$} \\
\hline$(n=45)$ & $M$ & -79 & 94 & 660 & -190 & 0.15 & 0.54 & 0.77 & 1.62 \\
\hline & S.D. & 6 & 7 & 90 & 20 & 0.02 & 0.04 & 0.09 & 0.55 \\
\hline \multicolumn{10}{|l|}{ Soleus } \\
\hline$(n=13)$ & $M$ & -73 & 85 & 390 & -125 & 0.24 & 0.80 & 1.06 & 1.45 \\
\hline & S.D. & 8 & 9 & 90 & 15 & 0.03 & 0.07 & 0.07 & 0.10 \\
\hline Difference & & $*$ & $* *$ & $* *$ & $* *$ & $* *$ & $* *$ & $* *$ & 0 \\
\hline
\end{tabular}


mean values of MU codes 004,107 and 418), so all IAPs $(n=45)$ of the FTG fibres were pooled; mean and standard deviation of the pooled data are also shown in Table I. The variable repolarization behaviour resulted in a large standard deviation in the $T_{3}$ characteristic.

\section{(3) The IAPs of slow soleus fibres}

The mean force of the slow soleus motor units was considerably less than that of the FTG EDL units, $22 \mathrm{mN}(\mathrm{n}=3)$ and $43 \mathrm{mM}(\mathrm{n}=6)$ respectively. The largest amplitude of the motor unit action potential seen during the surface EMG scanning tended to lower values for the slow units. We were not able to record IAPs of more than 5 fibres in any soleus experiment. Possibly, fewer fibres per motor unit and a lower density of the fibres in the motor unit territory decreased the chance of penetrating the fibres. Fig. 4 shows 3 IAPs of fibres belonging to the same slow soleus motor unit.

In Table I the data of the slow soleus fibres are summarized.

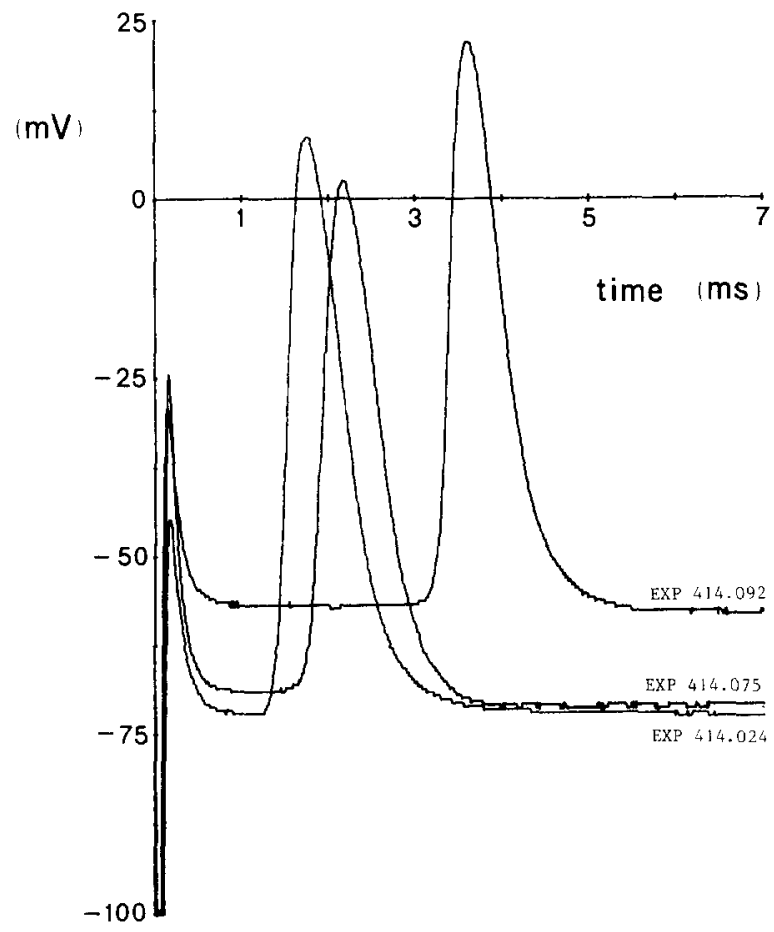

Fig. 4. Three intracellular action potentials in fibres of one slow soleus motor unit.

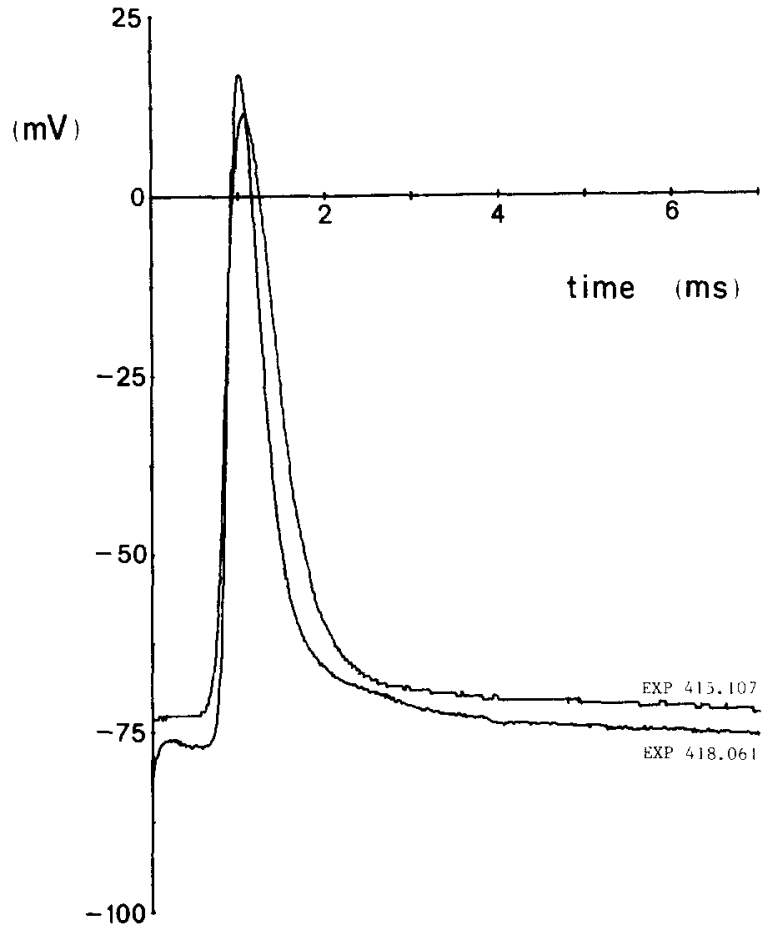

Fig. 5. A comparison between typical examples of intraceltular action potentials of FTG EDL and slow soleus muscle fibres.

(4) Comparison of the IAPS of FTG EDL and of slow soleus fibres

With the help of the mean values of the characteristics of both fibre populations the best representatives of the populations were chosen.

These two IAPs are shown in Fig. 5, which displays clearly the differences between them.

In the lower part of Table I the mean values of the characteristics of the FTG EDL and the slow soleus fibres are listed. The significance of the differences is indicated.

\section{Discussion}

Why is it important to stimulate motor units in experiments directed to IAP recording?

In order to state clearly the differences between the IAPs of fast and slow muscle fibres we have developed a method by which IAPs of fibres belonging to a single motor unit are measured. The motor unit type is determined as described in 
Methods. Since fibres of a motor unit show about equivalent histochemical properties (e.g., Nemeth et al. 1981) the type of the fibres in which IAPs were recorded is known.

With the stimulation methods used by other authors studying IAPs the fibre type cannot be established exactly. In their experiments only the choice of the muscle establishes the properties of fibres as more or less fast or slow on an average basis; e.g. 'slow' soleus and 'fast' EDL are heterogeneous; in adult rat these muscles contain $53 \%$ slow and $44 \%$ fast twitch glycolytic fibres respectively (histochemical data of Zuurveld, thesis University of Nijmegen 1984).

In the case of direct stimulation of a group of muscle fibres (Buller et al. 1966; Lewis 1972; Hanson 1974) the chance of disturbance of the IAP by active neighbouring fibres is rather high.

When the distance between the stimulating and recording electrodes is smaller than $0.7 \mathrm{~mm}$ there is no normal action potential at the recording site (Kerr and Sperelakis 1983). IAP records reported in the literature have been made at (very) small distances from the stimulating electrode, sometimes even with this electrode itself. The resulting deterioration cannot be quantified.

In our experiments the muscle fibres were activated via the end-plate and the recording micropipette was positioned about $3 \mathrm{~mm}$ away from the end-plate region. In order to avoid problems from the electrical effect on the action potential of the transition of the muscle fibres into the tendon, the distance between micropipette and tendon was also about $3 \mathrm{~mm}$.

The shape of the intracellular action potential depends on the condition of the muscle fibre and therefore, e.g., on the condition of the animal in in vivo experiments and on the bath fluid in in vitro experiments. We observed the condition of muscle by means of the twitch force and the shape of the action potential of the motor unit.

\section{IAPs recorded in vivo}

In vivo experiments directed to the recording of intracellular action potentials are scarce. Most data available concern human muscle fibres (Beranek 1964; Goodgold and Eberstein 1966; McComas et al. 1968). However, the records of these authors were not described in detail and quantitative analyses of the IAPs depicted were irrelevant because of the few examples given and of stimulus artefacts. The data cannot be linked to fibre types at all because of the mixture of types in human muscle (Schmalbruch 1970).

There are clear differences between the IAPs measured in fast and slow muscles of the cat (Buller et al. 1966; Lewis 1972) and of the rat (Fedorov 1969); in these muscles also there is a mixture of fibre types. We now discuss the in vivo data of the cat and rat together with the relevant in vitro data with respect to the fibre type.

\section{Differences in IAPs of fast and slow muscle fibres}

Only data will be referred to when they concern IAPs of extrafusal muscle fibres of cat (Buller et al. 1966; Lewis 1972), rat (Fedorov 1969; Hanson 1974; McArdle et al. 1980) or mouse (Luff and Atwood 1972). The temperature range covered in these papers is from 32 to $37^{\circ} \mathrm{C}$. Note that comparison of our data with the literature is only possible by considering the muscle fibres of fast and slow muscles as fast and slow fibres respectively.

These data, including ours, show that: (a) The mean resting membrane potential of fast fibres is more negative than that of slow fibres (only Luff and Atwood give equal resting membrane potentials). A different resting membrane potential is consistent with the prediction of Hoh and Salafsky (1971), based on differences in intracellular potassium concentrations in fast and slow fibres. (b) The IAP amplitude of the fast fibres exceeds the IAP amplitude of the slow fibres.

The maximum rate of depolarization of our fast fibres is steeper than that of our slow fibres. The difference is more pronounced than in the IAPs of Luff and Atwood (1972). This may be correlated with the mixture of fibre types and with the deviating resting membrane potential data of these authors. In spite of the manipulation of the resting membrane potential before stimulation to the same preset value in all fibres, McArdle et al. (1980) describe a steeper depolarization phase of fibres of fast muscle than in those of slow muscle.

The shorter time to peak of intracellular action potentials of fibres in the fast flexor hallucis longus 
muscle than of fibres in the slow soleus muscle (Buller et al. 1966) is compatible with our RT data.

The time to peak of the IAPs given by Buller et al. (1966), the duration given by Hanson (1974) and the time characteristic given by Fedorov (1969) are about comparable with our RT, $T_{1}$ and $T_{2}$ characteristics. In all instances the equivalent times of slow fibres are prolonged compared with those of the fast fibres, but the differences are again more pronounced in our characteristics than in the time characteristics of other authors.

FTG EDL and slow soleus fibre IAPs differ in all values listed in Table $I$ except for the $T_{3}$ characteristic representing a late part of the repolarization phase. The repolarization behaviour of the FTG EDL fibres is rather variable, but often displays a pronounced slowness. This phenomenon of fast fibres can also be seen in the papers of Hanson (1974, Fig. 3 IA) and of Lewis (1972, Fig. 7).

In conclusion, the differences between intracellular action potentials of FTG EDL and slow soleus muscle fibres are significant for all characteristics studied except for $T_{3}$. As a result the extracellular potentials of the two fibre types will differ also. But, as described in the Introduction. other factors simultaneously influence the extracellular potential as well. Whether the complex of factors will ultimately result in distinguishable single fibre extracellular action potentials or motor unit action potentials for slow and fast fibres or motor units will be studied in continuation of this work.

\section{Summary}

The time course of the intracellular action potential was studied quantitatively, because it is an important factor in the generation of electromyographic signals.

In in vivo preparations of the $\mathrm{m}$. EDL and $\mathrm{m}$. soleus of the rat single motor units were stimulated and intracellular action potentials were recorded in muscle fibres belonging to those motor units. In this arrangement it was possible to relate the intracellular action potential to the fibre type.
The intracellular action potentials of fast twitch glycolytic (FTG) EDL and of slow soleus fibres were described, using 8 characteristics. All characteristics but one differed significantly between the two fibre populations.

Comparing characteristics of intracellular action potentials of FTG fibres with slow fibres, it is concluded that: the resting membrane potential is more negative; the amplitude of the action potential is larger; the maximum rates of depolarization and repolarization are higher; and the shape of the repolarization phase is more variable.

\section{Résumé}

Différences entre les potentiels d'action intracellulaires de fibres musculaires rapides et lentes

Le décours temporel de potentiels d'action intracellulaires a été étudié quantitativement parce qu'il constitue un facteur important dans la genèse des signaux EMG.

Dans des préparations in vivo du muscle extensor digitorum longus (EDL) et du muscle soleus de rat, des unités motrices uniques ont été stimulées et des potentiels d'action intracellulaires ont été enregistrés dans des fibres appartenant à ces unités. Ces potentiels d'action ont pu être attribués à des fibres musculaires de caractère déterminé parce que les unités motrices auxquelles ces fibres appartenaient ont été identifiées par la méthode de la déplétion glycogénique ou par décours temporel de twitch contraction.

Les potentiels d'action intracellulaires de fibres à contraction rapide et à métabolisme glycolytique (EDL) et de fibres lentes (soleus) ont été analysés en se fondant sur 8 caractères. Des différences significatives entre potentiels des deux populations de fibres ont été observées pour tous les caractères sauf un.

La comparaison des potentiels d'action intracellulaires de fibres rapides et de fibres lentes a montré que les premières ont: un potentiel de membrane au repos plus élevé; une plus grande amplitude du potentiel d'action; des vitesses maximales de dépolarisation et de repolarisation plus grandes; la forme de la phase de dépolarisation est plus variable. 
The authors are indebted to Margot Klerkx and Elly van der Meer for careful histochemical analysis, to Ton Verloop for the preparation of the electrodes, to Gerrit Bultstra for valuable technical help and to Truus Steijlen for secretarial assistance.

\section{References}

Albuquerque, E.X. and Thesleff, S. A comparative study of membrane properties of innervated and chronically denervated fast and slow skeletal muscles of the rat. Acta physiol. scand., 1968. 73: 471-480.

Beranek, R. Intracellular stimulation myography in man. Electroenceph. clin. Neurophysiol., 1964, 16: 301-304.

Buller, A.J., Lewis, D.M. and Ridge, R.M.A.P. Some electrical characteristics of fast twitch and slow twitch skeletal muscle fibres in the cat. J. Physiol. (Lond.), 1966, 180: 29P-30P.

Close, R. Properties of motor units in fast and slow skeletal muscles of the rat. J. Physiol. (Lond.), 1967, 193: 45-55.

Fedorov, V.V. Peculiarities of bioelectric activity of fibres from fast and slow muscles in rat. Fiziol. Zh. (Mosk.), 1969, 55: 588-596. (In Russian.)

Gielen, F.L.H., Wallinga-De Jonge, W. and Boon, K.L. Electrical conductivity of skeletal muscle tissue: experimental results from different muscles in vivo. Med. biol. Engng Comput., 1984, 22: 569-577.

Goodgold, J. and Eberstein. A. Transmembrane potentials of human muscle cells in vivo. Exp. Neurol., 1966, 15: 338-346.

Griep, P.A.M., Pool, C.W., Lammerée, G.C., Wallinga-De Jonge, W., Seeder, T. and Donselaar, Y.E. Intramuscular and epimuscular microstimulation of single motor units. Neurosci. Lett., 1980, 17: 191-196.

Griep, P.A.M., Gielen, F.L.H., Boom, H.B.K., Boon, K.L., Hoogstraten, L.L.W., Pool, C.W. and Wallinga-De Jonge, W. Calculation and registration of the same motor unit action potential. Electroenceph. clin. Neurophysiol., 1982, 53: $388-404$.

Hanson, J. The effects of repetitive stimulation on the action potential and the twitch of rat muscle. Acta physiol. scand., 1974, 90: 387-400.

Hoh, J.F.Y. and Salafsky, B. Effects of nerve cross-union on rat intracellular potassium in fast-twitch and slow-twitch rat muscle. J. Physiol. (Lond.), 1971, 216: 171-179.

Kerr, L.M. and Sperelakis, N. Membrane alterations in skeletal muscle fibres of dystrophic mice. Muscle Nerve, 1983, 6: $3-13$.
Kugelberg. E. and Thornell, L.-E. Contraction time, histochemical type, and terminal cisternae volume of rat motor units. Muscle Nerve, 1983, 6: 149-153.

Lewis, D.M. The effect of denervation on the mechanical and electrical responses of fast and slow mammalian twitch muscle. J. Physiol. (Lond.), 1972, 222: 51-75.

Ludin, H.P. Pathophysiologische Grundlagen elektromyographischen Befunde bei Neuropathien und Myopathien. Georg Thieme Verlag, Stuttgart, 1977.

Luff. A.R. and Atwood, H.L. Membrane properties and contraction of single muscle fibers in the mouse. Amer. J. Physiol., 1972, 222: 1435-1440.

McArdle, J.J., Michelson, L. and d'Alonzo, A.J. Action potentials in fast- and slow-twitch mammalian muscles during reinnervation and development. J. gen. Physiol.. 1980, 75: 655-672.

McComas, A.J., Mrozek, K., Gardner-Medwin, D. and Stanton, W.H. Electrical properties of muscle fibre membranes in man. J. Neurol. Neurosurg. Psychiat., 1968, 31: 434-440.

Nemeth, P.M., Pette, D. and Vrbová, G. Comparison of enzyme activities among single muscle fibres within defined motor units. J. Physiol. (Lond.), 1981, 311: 489-495.

Rahman, A.N. and Luttrell, C.N. Albumen embedding method for frozen sectioning of fresh tissues for histochemical studies. Bull. Johns Hopk. Hosp., 1962, 110: 66-72.

Rosenfaick, P. Intra- and Extracellular Potential Fields of Active Nerve and Muscle Fibres. A Physico-mathematical Analysis of Different Models. Akademisk Forlag. Copenhagen, 1969.

Schmalbruch, H. Die quergestreiften Muskelfasern des Menschen. Ergebn. Anat. Entwickl.-Gesch., 1970, 43: 1-75.

Wallinga-De Jonge, W., Boom, H.B.K., Boon, K.L., Griep, P.A.M. and Lammerée, G.C. Force development of fast and slow skeletal muscle at different muscle lengths. Amer. J. Physiol., 1980, 239: C98-C104.

Wirtz, P., Wallinga-De Jonge, W. and Vermorken, A.J.M. An improved technique for the demonstration of glycogen depleted skeletal muscle fibres. Histochemistry, 1983a, 79: 141-142.

Wirtz, P., Loermans, H.M.Th., Peer, P.G.M. and Reintjes, A.G.M. Postnatal growth and differentiation of muscle fibres in the mouse. I. A histochemical and morphometrical investigation of normal muscle. J. Anat. (Lond.), 1983b. 137: 109-126.

Yonemura, K. Resting and action potentials in red and white muscles of the rat. Jap. J. Physiol., 1967, 17: 708-719. 